\title{
Unverricht-Lundborg disease (EPM1) in Finland
}

\section{A nationwide population-based study}

Jussi O.T. Sipilä, MD, DMSc, BSocSci, Jelena Hyppönen, MD, PhD, Ville Kytö, MD, DMSc, MSocSci, and Reetta Kälviäinen, MD, DMSc

Neurology ${ }^{\circledR}$ 2020;95:e3117-e3123. doi:10.1212/WNL.0000000000010911

\author{
Correspondence \\ Dr. Sipilä \\ jussi.sipila@utu.fi
}

\section{Abstract \\ Objective}

To investigate the epidemiology and prognosis of Unverricht-Lundborg disease (EPM1) in a nationwide, population-based setting.

\section{Methods}

Data from multiple registries were combined and analyzed. Clinical data were obtained from medical records. All patients treated for EPM1 in Finland between January 1, 1998, and December 31, 2016 were included.

\section{Results}

A total of 135 persons with EPM1 (54\% women) were identified and 105 were alive on December 31, 2016 (point prevalence 1.91/100,000 persons). The age-standardized (European Standard Population 2013) prevalence was $1.53 / 100,000$ persons. Annual incidence during the study period was $0.022 / 100,000$ person-years, with a mean age at onset of $9.4 \pm 2.3$ years (range $7.0-14.6$ years, no sex difference). The median age at death $(\mathrm{n}=34)$ was 53.9 years (interquartile range 46.4, 60.3; range 23.2-63.8), with no sex differences. The immediate cause of death was a lower respiratory tract infection in $56 \%$ of deaths. The survival rates of the patients were comparable to matched controls up to 40 years of age, but poorer during longterm follow-up (cumulative survival $26.4 \%$ vs $78.0 \%$ ), with a hazard ratio (HR) for death of 4.61. The risk of death decreased with increasing age at onset (HR 0.76 per year, $95 \%$ confidence interval $0.65-0.89$ ). In approximately $10 \%$ of all cases, the disease progression appeared very mild; some patients retained functional independence for decades.

\section{Conclusions}

Unverricht-Lundborg disease is rare in Finland but still more common than anywhere else in the world. The disease course appears somewhat more severe than elsewhere, disability mounts early, and death occurs prematurely. 


\section{Glossary}

$\mathbf{C I}=$ confidence interval; $\mathbf{C R H C}=$ Care Register for Health Care; EPM1 = progressive myoclonic epilepsy 1A; HR = hazard ratio; ICD-10 = International Classification of Diseases, 10th revision.

The clinical course of myoclonic epilepsy of Unverricht and Lundborg, or progressive myoclonic epilepsy 1A (EPM1) (OMIM \#254800), is variable but typically leads to accumulating disability and early retirement. ${ }^{1-3}$ The prognosis is believed to have become more favorable, but data on this issue are scarce, and absent concerning survival and mortality. ${ }^{1}$

The best-known areas of EPM1 occurrence are on the shores of the Baltic and Mediterranean Seas. Italy, Tunisia, Algeria, and Morocco are known to be endemic countries, as are certain areas in southern France, but the exact prevalence and incidence figures are not available. ${ }^{1}$ It also appears probable that the disease is underdiagnosed in many countries. ${ }^{4}$ Finland has been considered the area with the highest prevalence of Unverricht-Lundborg disease in the world, with an incidence of $1 / 20,000$ live births. ${ }^{5}$ However, the only estimates of its prevalence in the country $(0.71 / 100,000$ persons in the 1950 s and $1.14 / 100,000$ persons in 1972) are outdated and are not based on nationwide, systematically collected data. ${ }^{6,7}$

We aimed to investigate the current epidemiology and prognosis of Unverricht-Lundborg disease. Therefore, we conducted a nationwide, population-based systematic search for all cases in Finland for the 1998-2016 time period. Our clinical observations suggested that the prognosis remains markedly worse than in the general population.

\section{Methods}

\section{Study design and data source}

The Finnish Care Register for Health Care (CRHC) is a mandatory national registry maintained by the National Institute for Health and Welfare (THL). It contains information on all public hospital discharges and outpatient visits in the country. The CRHC was searched for all patients treated with the ICD-10 code G40.37 (dedicated to progressive myoclonic epilepsy in Finland) between January 1, 1998, and December 31, 2016. Patients with rare disorders such as EPM1 are diagnosed and usually treated in public sector hospitals, all of which are included in the $\mathrm{CRCH}$. Patient records of the persons identified through the registry were obtained for review in order to confirm the diagnosis and to collect clinical and genetic data. Genetic data were also provided by the only laboratory conducting cystatin B gene (CSTB) mutation analyses in Finland: HUSLAB. Dates and causes of death of the identified persons were collected from the obligatory national registry, maintained by the authority Statistics Finland. The data were obtained on October 1, 2018, which thus marks the end of the survival follow-up. The Statistics Finland authority also provided national population data. The total population of Finland was 5,503,297 on December 31, 2016 (prevalence date). For the survival analyses, survival data of 27,000 randomly selected sex- and age-matched (1:200) controls were provided by Statistics Finland. The diagnosis of manifest Unverricht-Lundborg disease was accepted if it met the current criteria. ${ }^{1}$ These patients constituted the study cohort from which all analyses are derived.

Kuopio University Hospital Epilepsy Center has been recruiting patients older than 12 years nationwide with genetically verified Unverricht-Lundborg disease to study deep phenotypegenotype correlation since $2006 .{ }^{2}$ This study database is not suitable for epidemiologic analyses due to the method of ascertainment, but it was used here to estimate the completeness of ascertainment in the current study using a capture-recapture method. The Kuopio University Hospital database was used for this purpose. All other analyses are derived from the CRHC, HUSLAB, and Statistics Finland searches and the hospital records of patients derived from those searches.

\section{Statistical analysis}

Shapiro-Wilk and Kolmogorov-Smirnov tests were used to assess the distribution of continuous variables, and, subsequently, the Student $t$ test, Mann-Whitney $U$ test, or independent samples Kruskal-Wallis test were used as appropriate. Cross-tabulation and the $\chi^{2}$ test were used to assess differences between groups when 2 variables were involved. A 2-source capture-recapture analysis was performed using the $\mathrm{CRCH}$ data (the primary source) and Kuopio University Hospital registry data (the secondary source) to evaluate the completeness of ascertainment using the inventory method. Age standardization was performed using the direct method, with the European Standard Population 2013 used as a reference. The Poisson method was used to calculate 95\% confidence intervals (CIs). The Kaplan-Meier method and Cox regression were used to analyze survival (from birth to death or end of follow-up). Matched regression was used for analyses of patients with EPM1 and controls. Multivariate Cox model of patients with EPM1 included age at onset, sex, and genetic status. Interaction term analyses were used to evaluate potential interactions between model variables and mortality. The median follow-up for survival was 46.1 years (interquartile range 34.5-56.0 years). $p$ Values less than 0.05 were considered significant. IBM SPSS Statistics, version 25 (IBM SPSS, Chicago, IL) and SAS 9.4 (SAS Institute Inc., Cary, NC) were used for statistical analyses.

\section{Standard protocol approvals, registrations, and patient consents}

This registry-based study was approved by THL (THL/ 1613/5.05.00/2017) and Statistics Finland (TK-53-1280-18). 
In addition, regional permits were required by some hospital districts, and they were obtained accordingly. Because the study involved no contact with patients, ethical committee approval was not needed. This was a retrospective register study, and thus no informed consent was required, and the participants were not contacted. The Kuopio University Hospital registry study was approved by the Kuopio University Hospital ethics committee, and informed consent was provided by all the participants or their guardians when applicable. The legal basis for processing personal data is public interest and scientific research (EU General Data Protection Regulation 2016/679 [GDPR], Article 6 [1] [e] and Article 9 [2] [j]; Data Protection Act, Sections 4 and 6).

\section{Data availability}

This article is based on third-party data. Access to data is regulated by Finnish law and the Finnish National Institute for Health and Welfare. The disclosure of data to third parties without explicit permission from THL is prohibited. Only those fulfilling the requirements established by Finnish law and THL for viewing confidential data are able to access the data. We confirm that the authors did not have any special access privileges that others would not have.

\section{Results}

\section{The cohort}

Unverricht-Lundborg disease was identified and verified in 135 persons (54\% women). In the capture-recapture analysis, 101 patients were found in both registries, 34 in only the $\mathrm{CRCH}$ data, and 45 in only the Kuopio University Hospital records, suggesting that the total EPM1 population in Finland would have been 180 patients (95\% CI 155-208), and hence our ascertainment of it $75 \%$ complete. The mean age at onset was $9.8 \pm 2.3$ years (95\% CI 9.4-10.2; figure 1A), ranging from 2 to 19 years (data available for 125 patients after excluding 1 outlier with an age at onset of 25 years in the 1960s and apparently erroneous data on this patient), and there was no difference between men $(10.1 \pm 2.4$ years, $95 \%$ CI 9.5-10.7) and women (9.5 \pm 2.4 years, $95 \%$ CI 8.9-10.1; $p=$ $0.16)$. Verification of the diagnosis by a genetic analysis was available for 101 patients (75\%), of whom 83 were homozygous for the dodecamer repeat expansion. Seven patients were compound heterozygotes, 4 of whom were carriers of the dodecamer expansion in one of the alleles and some other mutation in the second allele whereas the mutations were not further specified in the remaining 3 . In 11 patients, 2 mutations had been observed but their exact nature had not been recorded in the available data although the time period of testing suggests at least most of them were repeat expansion homozygotes.

\section{Disease course}

The mean age at losing the ability to walk without aid (data available for 50 patients) was $34.0 \pm 13.1$ years (range 12-64 years), and for becoming wheelchair-bound (data available for
47 patients) it was $35.9 \pm 14.0$ years (range $12-67$ years). A percutaneous gastrostomic feeding tube was given to $16 \mathrm{pa}-$ tients at a mean age of $49.7 \pm 10.0$ years (range 33.2-66.9 years, data on timing available for 13 patients), of whom 6 died within 2 years of receiving it. In approximately $10 \%$ of cases, the disease progression appeared very mild, and some of these patients retained functional independence for decades. In some cases, the patients were independent and working in middle age. For instance, one patient was working part-time and capable of driving a motorbike well past age 50. Another patient's diagnosis of juvenile myoclonic epilepsy was revised to EPM1 at age 54. A third patient manifested mild, nondisabling symptoms until age 56 and was working full-time in an academic occupation. These 3 patients were all confirmed dodecamer expansion homozygotes.

Of all patients with EPM1, 35 (25\%) died during the followup, with a median age at death of 53.9 years (interquartile

Figure 1 Age-related characteristics of Unverricht-Lundborg disease in Finland
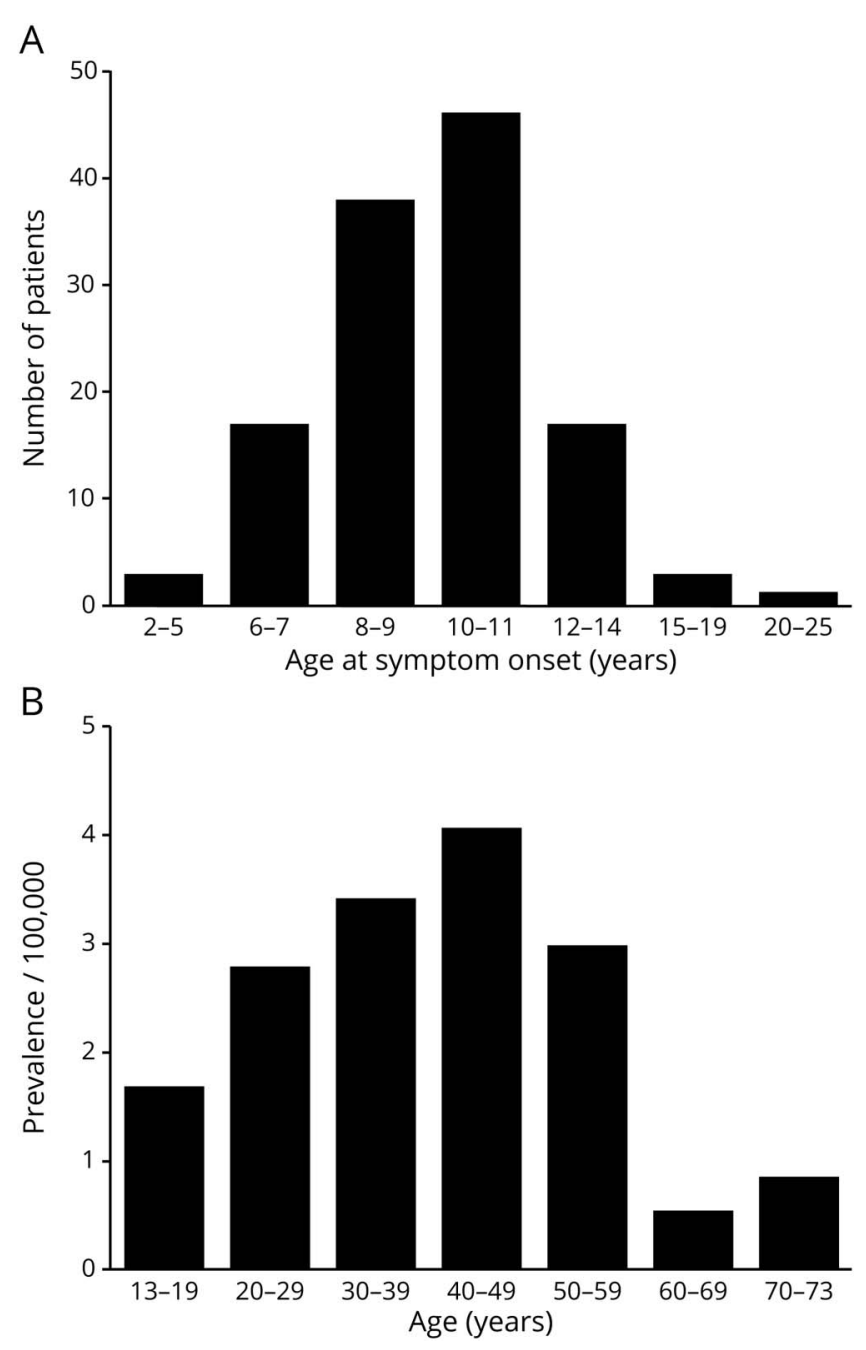

(A) Age at symptom onset in 125 patients. (B) Age-specific prevalence on December 31, 2016. 
range 46.4-60.3; range 23.2-63.8). The patients had poorer survival during long-term follow-up compared to the matched controls (cumulative survival $26.4 \%$ vs $78.0 \%$ ), with a hazard ratio (HR) for death of 4.61 (95\% CI 3.24-6.55; $p<0.0001$ ) (figure 2). Men had poorer survival among both patients and controls compared to women, but sex did not significantly affect the EPM1-associated mortality in the study population (interaction $p=0.165$ ). In a multivariate analysis of patients with EPM1, the hazard of death decreased with higher age at disease onset (HR 0.76 per year, 95\% CI 0.65-0.89) and was higher in men compared to women (HR 3.13, 95\% CI 1.37-7.14), whereas genetic status had no association with mortality $(p=0.99)$. There were no interactions between these variables $(p>0.87$ for all $)$.

The immediate cause of death in Unverricht-Lundborg disease was lower respiratory tract infection in $56 \%$ of the deceased patients. Suicide by drowning, cancer of the colon, alcoholic cirrhosis, biliary pancreatitis, erysipelas, unspecified sepsis, heart failure, cardiomegaly, and hemolytic-uremic syndrome were each an immediate cause of death in single cases. In the rest of the deceased patients, the death was attributed solely to EPM1.

\section{Incidence}

In total, 22 patients manifested and were diagnosed with Unverricht-Lundborg disease during the study period, yielding an annual incidence of $0.022 / 100,000$ person-years $(95 \%$ CI 0.014-0.33). No new diagnoses were made in the last 5 years of the study period. No noteworthy regional clustering was observed (location data unavailable for 2 patients), although none of the diagnoses were made in the 3 northernmost hospital districts (inhabited by $10.7 \%$ of the total population). Mean age at onset in these 22 patients was $9.4 \pm$

Figure 2 Cumulative survival from birth in 135 Finnish patients with Unverricht-Lundborg disease and 27,000 matched controls

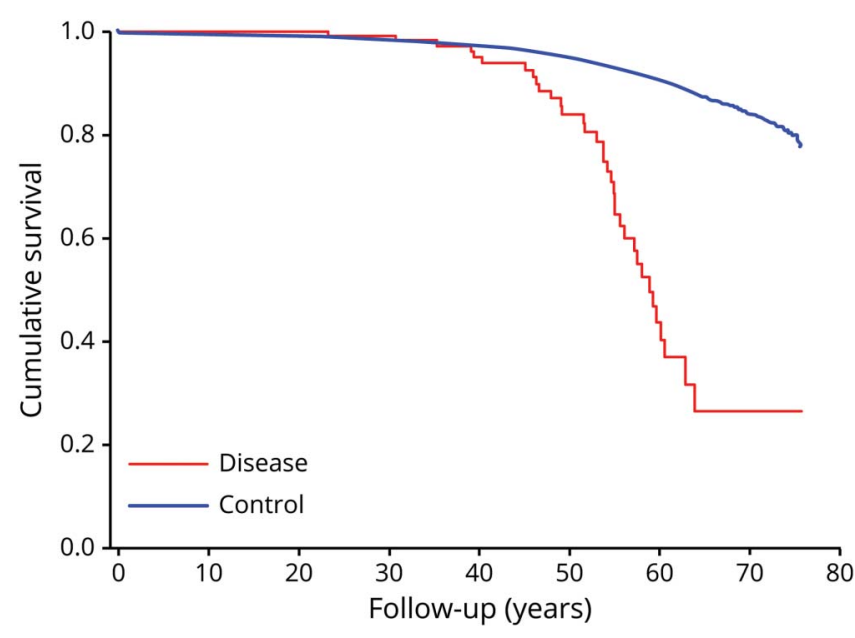

2.3 years, ranging from 7.0 to 14.6 years. They were all alive on the prevalence date, with a mean age of $22.7 \pm 4.9$ years (range 13.6-29.7 years), and most were independently ambulatory (data available for 15), but almost half had moved to an assisted living facility or been institutionalized (data available for 16). Only one of these patients died (at age 30.7 years due to hemolytic-uremic syndrome) before October 2018.

\section{Prevalence}

There were 105 patients alive on December 31, 2016, indicating a point prevalence of $1.91 / 100,000$ persons (95\% CI 1.56-2.31) on that day. The age-standardized prevalence (European Standard Population 2013) was 1.53/100,000 persons. The mean age of those who were alive was $40.6 \pm$ 13.6 years (range 13.6-74.0 years), and the age-specific prevalence was highest among the population 40-49 years of age (figure 1B). The majority of those who were alive and for whom data were available were ambulatory and half did not live in their own home (figure 3). Data on patients' hospital district at the time of diagnosis was available for 98 patients. The ratio of the proportion of all EPM1 diagnoses to the proportion of the total general population was generally higher in the eastern parts of Finland (figure 4).

\section{Discussion}

The prevalence of manifested and diagnosed EPM1 of 1.91/ 100,000 in Finland was the highest in the world. All cases in which genetic confirmation had been recorded and specified were associated with a homozygous CSTB dodecamer repeat expansion. The accumulation of disability was variable, but most of the patients experienced premature loss of independence, and survival after 40 years of age was poorer than in the population controls.

Considering that the KUH database started recruiting before the study period and has continued to recruit patients after it, our capture-recapture analysis is biased to showing poorer ascertainment than a comparison of databases with matching time periods would yield. Such datasets were not available. Therefore, the combined estimate from the capturerecapture analysis of the total population of 180 patients (implicating a prevalence of $2.5 / 100,000$ persons) is an overestimate and our ascertainment better than $75 \%$. Similar to previous reports, the disease appeared to be slightly more common in the eastern parts of the country. ${ }^{5-7}$ Also in agreement with previous reports from Finland, ${ }^{2}$ the disease was associated with dodecamer expansion in nearly all patients for whom data were available in our study, and the proportion of compound heterozygotes was low (8\%).

During the study period, the annual incidence was 0.022 / 100,000 person-years, suggesting that one new patient should be diagnosed every year in the country. Interestingly, the number of new diagnoses appeared to dwindle toward the end of the study period. The reasons for this are unknown, but a 

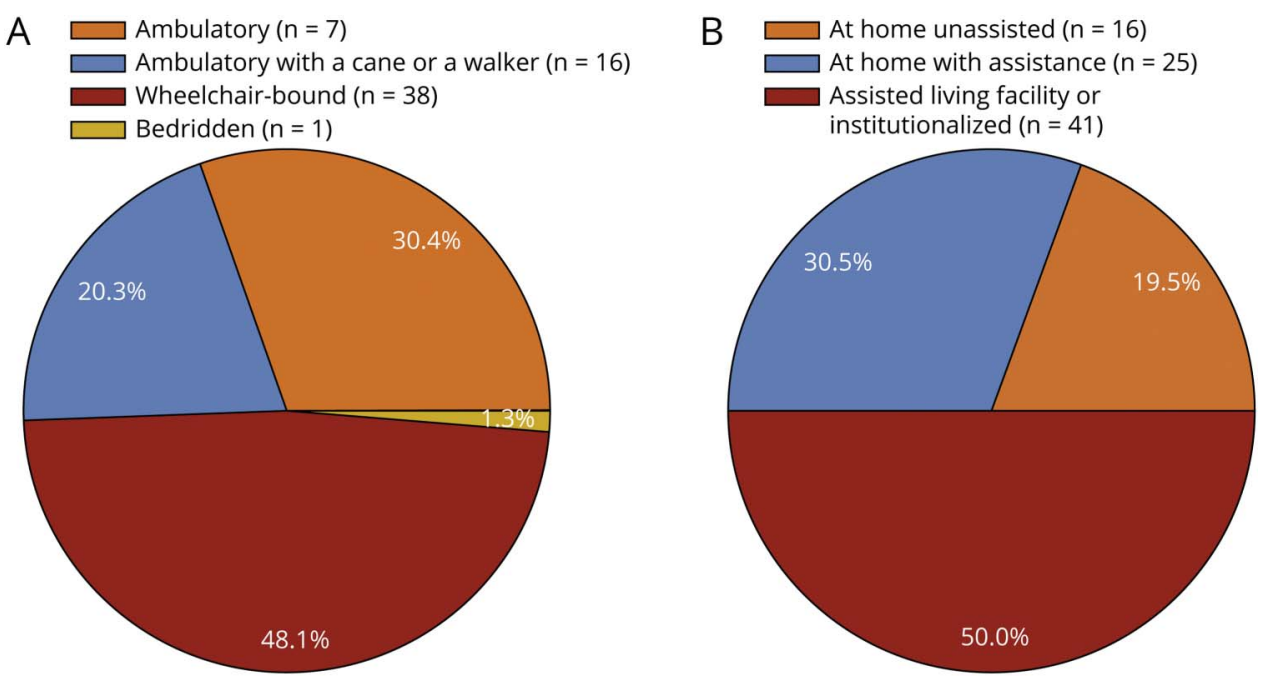

(A) Ambulation. (B) Domicile.

similar development in Finland has been observed concerning Huntington disease, another inherited neurologic disorder for which the causative mutation was identified in the $1990 \mathrm{~s},{ }^{8}$ probably due to diagnostic catch-up after the introduction of genetic testing for the disorder. The authors are aware of patients with EPM1 diagnosed after the study period in Finland, and longer follow-up is needed to verify a stable level of the annual number of new diagnoses. The clinical suspicion of EPM1 in mild cases can be challenging, leading to other more benign diagnoses at the disease onset. Furthermore, familial presentation of Unverricht-Lundborg disease mimicking juvenile myoclonic epilepsy has also been reported. ${ }^{9}$ Approximately $10 \%$ of the patients in our study exhibited a mild phenotype resembling previously described findings in some Finnish patients. ${ }^{5}$ Genetic testing should be used in juvenile myoclonic epilepsy if the patient's myoclonus symptoms are drug-resistant or if other progressive symptoms or abnormalities are observed upon neurologic examination. ${ }^{10}$

The average age at onset of around 10 years and the fact that onset nearly always occurred between 6 and 16 years of age in our study concurs with previously published results from Finland. ${ }^{2,5-7}$ These findings are slightly lower than the 12.3 years ${ }^{11}$ and 11.7 years ${ }^{3}$ reported in Italy and the 11.0 years ${ }^{4}$ observed in the Netherlands. Notably, all Italian patients in both of these studies were genetically verified, whereas in a quarter of the patients in the current study genetic verification was not recorded. However, a recent study using the Kuopio University Hospital database and reporting on 66 genetically verified patients-thus larger than either of the Italian studies-also reported that disease manifested at 10 years of age. ${ }^{2}$ It therefore appears that the disease manifests slightly earlier in Finland than in Italy. Considering that earlier onset was associated with worse prognosis, as also reported previously, ${ }^{2,3,5,9}$ it appears that, on average, the disease course of
Finnish patients is less favorable than in other populations. This is in agreement with the previously held general impression.

It is therefore not surprising that our results concerning disease prognosis are slightly worse than those in Italy. A recent Italian study reported that myoclonus became disabling on average 32 years after disease onset, and cognitive impairment manifested approximately 3 years later. ${ }^{3}$ The authors also reported that most patients had become unable to work almost a decade before either of these circumstances occurred. In the current study, the individuals who lost their ambulatory ability did so on average during the fourth decade of life. However, our analyses did not take into account those patients who had not reached these end points at the end of the study period, and accurate data on the timing of these occurrences were missing for some patients in whom they had occurred. Therefore, our results concerning disability should be interpreted cautiously. Indeed, out of the 66 patients in the recent Finnish study on EPM1 phenotype, 36 were able to walk independently at an average age of 33 years, although patients in better health were more likely to have attended the study visit. ${ }^{2}$ Nevertheless, the fact that almost half of the patients diagnosed in 1998-2016 were unable to live in their own homes by December 31, 2016 (when they were younger than 23 years on average) indicates that disability often occurs early. Interestingly, a genetically verified case series of 8 patients from the United Kingdom reported an even worse motor prognosis, with half of the patients being wheelchairbound by a mean age of 22.3 years (range 20-24 years). ${ }^{12}$

Our results on age at death and survival are far more robust. Indeed, considering that some patients with UnverrichtLundborg disease born in the same decades as our cohort's oldest patients had more than likely died before our study period, and as there is a small immortal time bias in our survival analysis 
Figure 4 Ratio of Unverricht-Lundborg disease diagnoses (data available for 98) to the proportion of general population by area

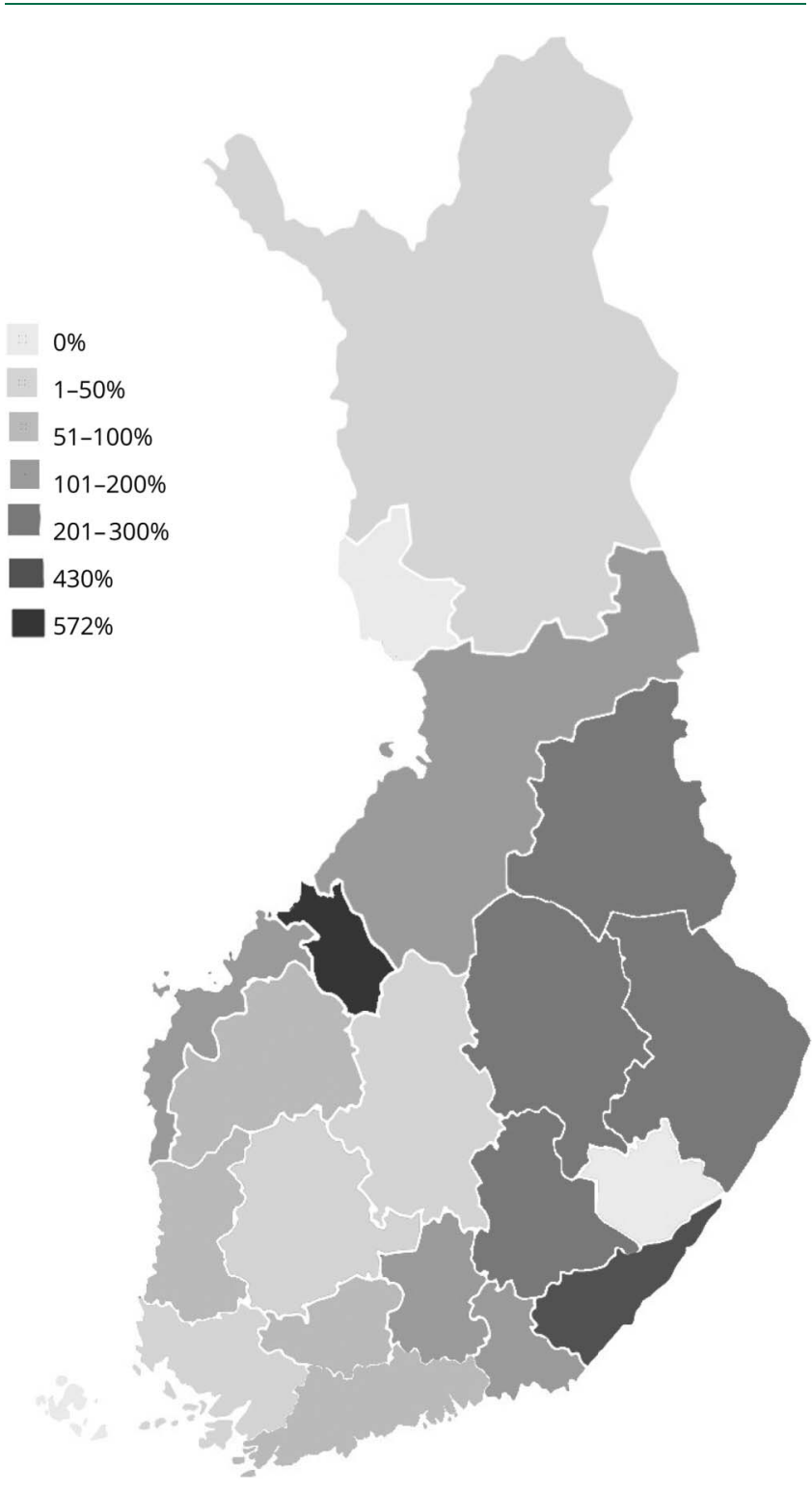

favoring the patients with EPM1, our data even more convincingly show that persons with Unverricht-Lundborg disease die prematurely. According to our data, survival did not differ between patients and controls before age 40, but after that age the difference was marked and progressive. Unexpected deaths in EPM1 are usually associated with the disease, ${ }^{13}$ and it appears that most deaths observed in the current study were also complications of severe or advanced disease. Although survival with EPM1 was lower in men compared to women in our study, this difference was attributable to the overall difference in life expectancy between men and women in Finland (6.5 years both in 1951-1955 and 2010). Nevertheless, survival appears to be markedly better than in previous EPM1 studies that reported any data on the subject from Finland. ${ }^{6,7}$
As this was a registry-based retrospective study, there are methodologic weaknesses associated with the design. The most notable is the possibility of erroneously coded registry data, which may lead to underascertainment. An effort was made to balance this using the Kuopio University Hospital database for a capture-recapture analysis, but because the data sets are not entirely comparable some uncertainty remains. Furthermore, patient charts inevitably contain heterogeneity in recording, and some data are likely to be missing. We therefore concentrated our analyses on the most robust parts of the data, and the results on disability accumulation should be interpreted cautiously. More patients with compound heterozygosity are needed to verify our results of an absence of association between genetic status and mortality. The strengths of the study include its nationwide setting, with complete coverage of pertinent health care units, and the proven reliability of CRHC as a data source. ${ }^{14}$

Unverricht-Lundborg disease is rare in Finland, but it is more common there than anywhere else in the world. The disease course appears to be somewhat more severe in Finland than elsewhere, with disability mounting early and death occurring prematurely. Nevertheless, in some cases the disease course is mild, with functional independence and the ability to work retained well into middle age.

\section{Acknowledgment}

The authors thank Dr. Marja Hietala for her help in designing the study.

\section{Study funding}

This study was supported by grants from the Maire Jokinen Foundation. The sponsor had no role in study design, data collection, data analysis, data interpretation, or writing of the article. The authors had full and unimpeded access to all data and the final responsibility for the decision to submit for publication.

\section{Disclosure}

J.O.T. Sipilä has received honoraria (Merck, Pfizer, Sanofi), consultancy fees (Rinnekoti Foundation, Medaffcon), travel grants and congress sponsorship (AbbVie, Orion Pharma, Merck Serono, Sanquin, Lundbeck, Novartis), and holds shares (Orion Corporation). J. Hyppönen has no conflicts of interests to report. V. Kytö has received speaker's honoraria (Bayer, BoehringerIngelheim), honoraria for membership of the advisory board (AstraZeneca), and travel grants and congress sponsorship (AstraZeneca, MSD). R. Kälviäinen has received grants from the Academy of Finland and Saastamoinen Foundation; speaker's honoraria from Eisai, UCB, and Orion; and honoraria for membership of the advisory boards of Eisai, Fennomedical, GW Pharmaceuticals, Marinus Pharmaceuticals, Sage Therapeutics, Takeda, and UCB. Go to Neurology.org/N for full disclosures.

\section{Publication history}

Received by Neurology April 21, 2020. Accepted in final form July 22, 2020. 


\section{Appendix Authors}

\begin{tabular}{|c|c|c|}
\hline Name & Affiliation & Contribution \\
\hline $\begin{array}{l}\text { Jussi Sipilä, } \\
\text { MD, DMSc, } \\
\text { BSocSci }\end{array}$ & $\begin{array}{l}\text { North Karelia Central } \\
\text { Hospital, Joensuu; and } \\
\text { University of Turku and } \\
\text { Turku University Hospital }\end{array}$ & $\begin{array}{l}\text { Designed and } \\
\text { conceptualized the study, } \\
\text { major role in the } \\
\text { acquisition of data, } \\
\text { performed statistical } \\
\text { analyses, analyzed and } \\
\text { interpreted the data, } \\
\text { drafted the manuscript }\end{array}$ \\
\hline $\begin{array}{l}\text { Jelena } \\
\text { Hyppönen, } \\
\text { MD, PhD }\end{array}$ & $\begin{array}{l}\text { Kuopio University Hospital } \\
\text { and University of Eastern } \\
\text { Finland, Kuopio }\end{array}$ & $\begin{array}{l}\text { Acquisition of data, } \\
\text { interpreted the data, } \\
\text { revised the manuscript for } \\
\text { intellectual content }\end{array}$ \\
\hline $\begin{array}{l}\text { Ville Kytö, } \\
\text { MD, DMSc, } \\
\text { MSocSci }\end{array}$ & $\begin{array}{l}\text { Turku University Hospital } \\
\text { and University of Turku }\end{array}$ & $\begin{array}{l}\text { Analyzed and interpreted } \\
\text { the data, performed the } \\
\text { survival analysis, provided } \\
\text { the figures, revised the } \\
\text { manuscript for intellectual } \\
\text { content }\end{array}$ \\
\hline $\begin{array}{l}\text { Reetta } \\
\text { Kälviäinen, } \\
\text { MD, DMSc }\end{array}$ & $\begin{array}{l}\text { Kuopio University Hospital } \\
\text { and University of Eastern } \\
\text { Finland, Kuopio }\end{array}$ & $\begin{array}{l}\text { Designed and } \\
\text { conceptualized study, } \\
\text { interpreted the data, } \\
\text { analyzed the data, revised } \\
\text { the manuscript for } \\
\text { intellectual content, } \\
\text { supervised the study }\end{array}$ \\
\hline
\end{tabular}

\section{References}

1. Kälviäinen R, Khyuppenen J, Koskenkorva P, Eriksson K, Vanninen R, Mervaala E. Clinical picture of EPM1-Unverricht-Lundborg disease. Epilepsia 2008;49: $549-556$.

2. Hyppönen J, Äikiä M, Joensuu T, et al. Refining the phenotype of UnverrichtLundborg disease (EPM1) a population-wide Finnish study. Neurology 2015;84: 1529-1536.

3. Canafoglia L, Ferlazzo E, Michelucci R, et al. Variable course of Unverricht-Lundborg disease early prognostic factors. Neurology 2017;89:1691-1697.

4. de Haan GJ, Halley DJ, Doelman JC, et al. Unverricht-Lundborg disease: underdiagnosed in The Netherlands. Epilepsia 2004;45:1061-1063.

5. Norio R, Koskiniemi M. Progressive myoclonus epilepsy: genetic and nosological aspects with special reference to 107 Finnish patients. Clin Genet 1979;15:382-398.

6. Harenko A, Toivakka EI. Myoclonus epilepsy (Univerricht-Lundborg) in Finland. Acta Neurol Scand 1961;37:282-296.

7. Koskiniemi M, Donner M, Majuri H, Haltia M, Norio R. Progressive myoclonus epilepsy: a clinical and histopathological study. Acta Neurol Scand 1974;50:307-332.

8. Sipilä JO, Hietala M, Siitonen A, Päivärinta M, Majamaa K. Epidemiology of Huntington's disease in Finland. Parkinsonism Relat Disord 2015;21:46-49.

9. Berrechid AG, Bendjebara M, Bouteiller D, et al. Juvenile myoclonic epilepsy phenotype in a family with Unverricht-Lundborg disease. Epileptic Disord 2019;21: 359-365.

10. Crespel A, Ferlazzo E, Franceschetti S, et al. Unverricht-Lundborg disease. Epileptic Disord 2016;18:28-37.

11. Magaudda A, Ferlazzo E, Nguyen VH, Genton P. Unverricht-Lundborg disease, a condition with self-limited progression: long-term follow-up of 20 patients. Epilepsia 2006;47:860-866.

12. Chew NK, Mir P, Edwards MJ, et al. The natural history of UnverrichtLundborg disease: a report of eight genetically proven cases. Mov Disord 2008; 23:107-113.

13. Khiari HM, Franceschetti S, Jovic N, Mrabet A, Genton P. Death in UnverrichtLundborg disease. Neurol Sci 2009;30:315-318.

14. Sund R. Quality of the Finnish hospital discharge register: a systematic review. Scand J Public Health 2012;40:505-515. 


\section{Neurology}

\section{Unverricht-Lundborg disease (EPM1) in Finland: A nationwide population-based study \\ Jussi O.T. Sipilä, Jelena Hyppönen, Ville Kytö, et al.}

Neurology 2020;95;e3117-e3123 Published Online before print September 17, 2020

DOI 10.1212/WNL.0000000000010911

This information is current as of September 17, 2020

\section{Updated Information \&} Services

References

Subspecialty Collections

Permissions \& Licensing

Reprints including high resolution figures, can be found at: http://n.neurology.org/content/95/23/e3117.full

This article cites 14 articles, 2 of which you can access for free at: http://n.neurology.org/content/95/23/e3117.full\#ref-list-1

This article, along with others on similar topics, appears in the following collection(s):

All Epilepsy/Seizures

http://n.neurology.org/cgi/collection/all_epilepsy_seizures Incidence studies

http://n.neurology.org/cgi/collection/incidence_studies

Natural history studies (prognosis)

http://n.neurology.org/cgi/collection/natural_history_studies_prognosis

\section{Prevalence studies}

http://n.neurology.org/cgi/collection/prevalence_studies

Information about reproducing this article in parts (figures,tables) or in its entirety can be found online at:

http://www.neurology.org/about/about_the_journal\#permissions

Information about ordering reprints can be found online:

http://n.neurology.org/subscribers/advertise

Neurology ${ }^{\circledR}$ is the official journal of the American Academy of Neurology. Published continuously since 1951, it is now a weekly with 48 issues per year. Copyright Copyright ( 2020 The Author(s). Published by Wolters Kluwer Health, Inc. on behalf of the American Academy of Neurology.. All rights reserved. Print ISSN: 0028-3878. Online ISSN: 1526-632X.

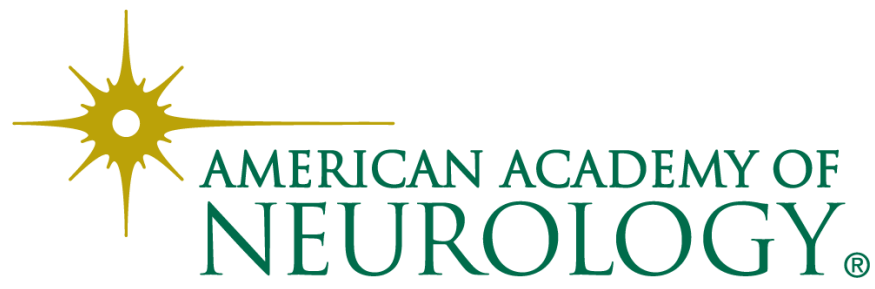

